\title{
La protección reforzada en España de los terceros afectados por el decomiso de bienes ilícitos ${ }^{1}$
}

\author{
The special protection in Spain for third parties \\ supporting the forfeiture of illicit assets
}

A proteção especial dos terceiros afetados pelo confisco
de bens derivados de atos ilícitos na Espanha

Nicolás Rodríguez-García ${ }^{2}$

Universidad de Salamanca - España

nicolas@usal.es

http://orcid.org/0000-0003-0045-796X

Omar Gabriel Orsi ${ }^{3}$

Ministerio Fiscal - Argentina

ogorsi@gmail.com

https://orcid.org/0000-0002-2803-1154

Resumen: España ha profundizado sus políticas de decomiso de bienes ilícitos de modo de lograr mayor eficiencia en la prevención y persecución de delitos. En esa línea, el decomiso trasciende a la persona penalmente

1 Este trabajo se ha elaborado en el marco de dos Proyectos de Investigación, uno del Ministerio de Economía y Competitividad (DER2016-79895-P) y otro de la Junta de Castilla y León (SA129G18). Ambos autores son investigadores del «Grupo de Investigación Reconocido Justicia, sistema penal y criminología» de la Universidad de Salamanca, así como de su Centro de Investigación para la Gobernanza Global (CIGG-USAL).

2 Catedrático Derecho Procesal en la Universidad de Salamanca (España). Doctor en Derecho. Director del «Programa de Doctorado en Estado de Derecho y Gobernanza Global», del «Máster Universitario en Estrategias anticorrupción y políticas de integridad», del «Máster Iberoamericano en Políticas Anticorrupción (on-line)» y del «Máster Iberoamericano en Compliance (on-line)».

3 Ministerio Fiscal (Argentina). Doctor en Derecho. 
responsable para alcanzar a terceros poseedores de bienes. La búsqueda de mayor eficiencia pone así en tensión dos principios fundamentales del ordenamiento jurídico: de un lado, enfrentar con eficiencia las conductas delictivas; del otro lado, la necesidad de conservar los principios del debido proceso y de resguardar el derecho de propiedad. El trabajo busca explorar esta tensión abordando, en una primera sección, la regulación jurídica de la figura del decomiso de bienes ilícitos en posesión de terceros ajenos al delito. Con posterioridad, se enfoca la necesaria intervención de esas personas en el proceso penal, ante la eventual aplicación del instituto de decomiso.

Palabras clave: bienes ilícitos; decomiso; terceros poseedores; derecho de propiedad; debido proceso.

ABSTRACT: Spain has developed its legal framework regarding the forfeiture of illicit assets in order to increase efficiency in the prevention and the repression of crimes. To reach that goal, the forfeiture transcends the individual responsible for the crime, reaching third parties in possession of the assets. This quest to reach higher standards of efficiency brings tension between two fundamental principles of the legal framework: on the one hand, to fight crimes efficiently; on the other hand, to preserve due process and property rights. This paper discusses this tension analyzing, in the first section, the legal framework for the forfeiture of assets in possession of third parties unrelated to the crime. The following section focuses on the mandatory intervention of these individuals in the criminal process as a consequence of the asset forfeiture.

KeYwords: illicit assets; forfeiture; third parties (in possession of assets); property rights; due process.

Resumo: A Espanha tem desenvolvido sua política de confisco de bens derivados de atos ilícitos para aumentar a eficiência na prevenção e na persecução de delitos. Nesse sentido, a recuperação de ativos transcende o âmbito da pessoa penalmente responsável pelos delitos e alcança terceiros que possuam os bens. A busca de maior eficiência coloca tensão entre dois princípios fundamentais do sistema jurídico: por um lado, a necessidade de enfrentar com eficiência as condutas delituosas; por outro, a necessidade de garantir os princípios do devido processo legal e de resguardar os direitos relacionados à propriedade. Este trabalho tem a finalidade de explorar essa tensão e aborda, em uma primeira seção, o regime jurídico da figura de confisco de ativos ilícitos em posse de terceiros não responsáveis pelo 
delito. Posteriormente se enfoca a intervenção necessária dessas pessoas no processo penal diante da possibilidade de utilização do instituto de confisco de bens.

Palavras-chave: bens derivados de atos ilícitos; confisco; terceiros interessados; direito de propriedade; devido processo legal.

SumARIO: I. Acotaciones introductorias. II. Decomiso de bienes de terceros. III. Intervención de terceros en el proceso penal. IV. Conclusiones. V. Referencias bibliográficas.

\section{ACOTACIONES INTRODUCTORIAS}

Dentro de las políticas de recuperación de activos ilícitos, el instituto del decomiso - y sus variaciones ${ }^{4}$ - están de moda ${ }^{5}$, tanto en países del common law como del civil law ${ }^{6}$, a consecuencia de las expectativas en él

4 Vid. BRUN, Jean-Pierre; GRAY, Larissa; SCOTT, Clive; STEPHENSON, Kevin M. Asset Recovery Handbook: A Guide for Practitioners. Washington: The International Bank for Reconstruction and Development / The World Bank, p. 103 y ss., 2011.

5 Vid. en detalle, con relación a esta institución jurídica en el sistema penal español, GARRIDO CARRILLO, Francisco Javier. El decomiso: innovaciones, deficiencias y limitaciones en su regulación sustantiva y procesal. Madrid: Dykinson, 2019; CARRILLO DEL TESO, Ana Elena. Decomiso y recuperación de activos en el sistema penal español. Valencia: Tirant lo Blanch, 2018; MARTÍNEZ ARRIETA MÁRQUEZ DE PRADO, Cristina. El decomiso y la recuperación y gestión de activos procedentes de actividades delictivas. Valencia: Tirant lo Blanch, 2018; RODRÍGUEZ-GARCÍA, Nicolás. El decomiso de activos ilícitos. Pamplona: Aranzadi, 2017; OCAÑA RODRÍGUEZ, Antonio. Medidas cautelares reales en el proceso penal y decomiso. Madrid: Sepín, 2016.

6 Vid. BOUCHT, Johan. The Limits of Asset Confiscation. On the Legitimacy of Extended Appropriation of Criminal Proceeds. London: Hart Publishing, p. 95 y ss., 2017; VV.AA. Common Law Legal Systems Model Legislative Provisions on Money Laundering, Terrorism Financing, Preventive Measures and Proceeds of Crime. London: Commonwealth Secretariat, p. 55 y ss., 2016; ALLDRIDGE, Peter. Money Laundering Law. Forfeiture, Confiscation, Civil Recovery, Criminal Laundering and Taxation of the Proceeds of Crime. London: Hart Publishing, p. 71 y ss., 2003. Y más: a mayores del juego procesal que el decomiso pueda desempeñar en las actuaciones jurisdiccionales nacionales, el decomiso 
localizadas para combatir la corrupción, el crimen organizado, el blanqueo de capitales y la delincuencia económica ${ }^{7}$, se encuentra naturalmente asociado a los elementos patrimoniales del responsable penal ${ }^{8}$, sin que pueda extenderse a quienes no han tenido vinculación con el delito o hayan adquirido los bienes de buena fe, es decir, a partir de una transmisión legal y carente de hasta elementos negligentes que la puedan enturbiar ${ }^{9}$, buscado con ello ser respetuosos con la seguridad del tráfico patrimonial ${ }^{10}$. Unas personas que, como fácilmente se infiere, no han sido declarados culpables de infracción penal alguna ${ }^{11}$, ni tan siquiera responsable civil ${ }^{12}$.

también puede estar presente en el proceso ante la Corte Penal Internacional, como estudia BUJOSA VADELL, Lorenzo Mateo. La perspectiva procesal del decomiso. In: CASTILLEJO MANZANARES, Raquel (dir.). El nuevo proceso penal sin Código Procesal Penal. Barcelona: Atelier, p. 688 y ss., 2019.

7 Vid. TRINCHERA, Tommaso. Confiscation and asset recovery: Better tools to fight bribery and corruption crime. Criminal Law Forum, p. 1 y ss., 2020; RUZ GUTIÉRREZ, Pablo Rafael. Prevención, sanción y recuperación de activos de la corrupción: la experiencia española. In: FERNÁNDEZ BLANCO, Carolina; FERRER BELTRÁN, Jordi (dirs.). Seguridad jurídica, pobreza y corrupción en Iberoamérica. Madrid: Marcial Pons, p. 185 y ss., 2018; FERNANDEZ-BERTIER, Michaël. The History of Confiscation Laws: From the Book of Exodus to the War on White-Collar Crime. In: LIGETI, Katalin; SIMONATO, Michele (eds.). Chasing Criminal Money. Challenges and Perspectives on Asset Recovery in the EU. London: Hart Publishing, p. 53 y ss., 2017. Unos delitos cuyo leiv motiv fundamental es obtener, de la manera más rápida y segura, un beneficio económico, y ello, como enfatiza NOREÑA SALTO, ya se encuentre plasmado como elemento subjetivo del tipo - denominado ánimo de lucro- como si simplemente está implícito en la actividad delictiva. Cfr. NOREÑA SALTO, José Ramón. El procedimiento de decomiso autónomo. In: VV.AA. El decomiso: aspectos sustantivos y procesales. Madrid: Centro de Estudios Jurídicos, p. 3, 2020. En función del decomiso final, producto del dictado de una sentencia firme, o, dadas ciertas condiciones, de manera anticipada: por caso, cuando el órgano judicial competente vaya a acordar la destrucción de los bienes decomisados (art. 367 ter 1.I in fine LECR).

$9 \quad$ Vid. QUINTERO OLIVARES, Gonzalo. Sobre la ampliación del comiso y el blanqueo, y la incidencia en la receptación civil. Revista Electrónica de Ciencia Penal y Criminología, n. 12-rl, p. 2 y ss., 2010.

10 GARCÍA CAVERO, Percy. El decomiso de bienes relacionados con el delito en la legislación penal peruana. Derecho PUCP, n. 81, p. 122-123, 2018.

11 URIARTE VALIENTE, Luis María. 21 cuestiones sobre el decomiso: Disposiciones generales, decomiso directo y de sustitución. VV.AA. El decomiso: aspectos sustantivos y procesales. Madrid: Centro de Estudios Jurídicos, p. 7, 2020.

Vid. STS de 27 de junio de 2003 (n. 928). 
Fue en el terreno del blanqueo de capitales donde el legislador penal prestó particular atención a la hora de precisar las excepciones a este postulado ${ }^{13}$ : el principio de buena fe queda exceptuado, en materia de blanqueo, cuando se haya prestado alguna forma de ayuda al sujeto pasivo del proceso penal para eludir su responsabilidad patrimonial, asumiendo, de manera real o ficticia, la titularidad de los bienes a decomisar, y obstaculizando con ello la acción de la justicia antes del dictado del decomiso ${ }^{14}$. Una respuesta jurídica que permite decomisar sin castigar ${ }^{15}$ al darse situaciones patrimoniales ilícitas, pero con relación a la cual no existe ni consenso doctrinal ni jurisprudencial con relación a su naturaleza civil o sancionadora, dicotomía para nada baladí por cuanto la opción por una u otra tiene importantes consecuencias en los derechos, garantías y principios que son de aplicación a partir del marco jurídico que vamos a exponer ${ }^{16}$.

13 Vid. QUINTERO OLIVARES, Gonzalo. El procedimiento especial y autónomo para el comiso. In: QUINTERO OLIVARES, Gonzalo (coord.). Comentarios a la reforma penal de 2015. Pamplona: Aranzadi, p. 300 y ss., 2015. El tercero puede ser alcanzado, en principio, por el contenido de la resolución judicial sobre la responsabilidad civil del art. $122 \mathrm{CP}$ : quien por título lucrativo hubiere participado de los efectos de un delito, está obligado a la restitución de la cosa o al resarcimiento del daño hasta la cuantía de su participación. Más ampliamente vid. RASILLO LÓPEZ, Pilar. El decomiso. Cuadernos Digitales de Formación, n. 3, p. 17 y ss., 2017; GÓMEZ TOMILLO, Manuel. La responsabilidad civil de las personas jurídicas: especial problemática del tercero lucrativo. Cuadernos Digitales de Formación, n. 19, p. 11 y ss., 2016; DÍAZ LÓPEZ, Juan Alberto. El partícipe a título lucrativo tras las reformas del decomiso. Diario La Ley, n. 8667, p. 4 y ss., 2015; SÁEZ-SANTURTÚN PRIETO, Miguel. El responsable civil a título lucrativo: artículo 122 del Código Penal. Diario La Ley, n. 8497, p. 1 y ss., 2015.

14 Bajo esta lógica, poco importa la naturaleza del sujeto que incurre en mala fe, y si está unido al sujeto pasivo del proceso penal principal por lazos familiares o afectivos - un allegado, según la expresión utilizada en instrumentos jurídicos previos-, o económicos. En detalle con relación a este delito vid. MARTÍN SAGRADO, Óscar. El decomiso en la investigación y enjuiciamiento del delito de blanqueo de capitales». Revista General de Derecho Penal, n. 31, p. 29 y ss., 2019.

15 Modalidad distinta al decomiso ampliado y sin condena, debido a que, como estudia en detalle CASTELLVÍ MONSERRAT, Carlos. Decomisar sin castigar. Utilidad y legitimidad del decomiso de ganancias. InDret: Revista para el Análisis del Derecho, n. 1, p. 4 y ss., 2019, recae sobre personas distintas a las que deberían ser castigadas por el delito que ha originado los instrumentos, efectos y ganancias.

16 SSTS de 30 de mayo de 2007 (n. 450); de 7 de junio de 2019 (n. 299). Más ampliamente vid. FARTO PIAY, Tomás. Los terceros afectados por el decomiso 
Pero más allá de la mayor o menor precisión que pueda alcanzar el legislador, es claro que la demarcación entre la regla y la excepción no responde a una operación abstracta, sino que requiere de una indagación, de un proceso de conocimiento que establezca en qué ocasiones, y por qué motivos, cabrá extender el decomiso a bienes ubicados bajo el dominio de terceros ${ }^{17}$. Es por ello que la DIR 2014/42/UE ${ }^{18}$ recurre a la expresión «personas afectadas» cuando se dedica a ordenar a los países miembros que adopten las medidas necesarias para garantizarles una tutela judicial efectiva y un juicio justo, a fin de preservar sus derechos (art. 8.1).

Es en el terreno práctico donde queda claro que la vinculación con el delito y la mala fe no son extremos de fácil acreditación, como lo ha enseñado la operativa en muchos litigios penales ${ }^{19}$, ya frustrando la eficacia del decomiso, ya ralentizando y encareciendo las actuaciones judiciales. Estas dificultades fueron las que motorizaron, a la postre, una

ante el proceso penal. In: BERDUGO GÓMEZ DE LA TORRE, Ignacio: FABIÁN CAPARRÓS, Eduardo Ángel; RODRÍGUEZ-GARCÍA, Nicolás (edits.). Decomiso y recuperación de activos. Crime doesn't pay. Valencia: Tirant lo Blanch, 2020 - en prensa-.

17 Vid. SSTS de 16 de julio de 2001 (n. 1410); de 16 de marzo de 2004 (n. 339); de 12 de noviembre de 2008 (n. 798); de 13 de noviembre de 2014 (n. 746); de 23 de marzo de 2017 (n. 183); de 4 de febrero de 2019 (n. 48); de 16 de octubre de 2019 (n. 493).

Directiva 2014/42/UE del Parlamento Europeo y del Consejo, de 3 de abril de 2014, sobre el embargo y el decomiso de los instrumentos y del producto del delito en la Unión Europea [DOUE n. L 127, de 29 de abril de 2014]. Destacar como en el ámbito internacional es de gran ayuda, tanto para las actuaciones jurisdiccionales patrias como para resolver los pedidos de auxilio y cooperación judicial internacional, el tener un texto normativo de referencia que haya servido, cuando menos, de orientación en los procesos de reforma legislativa de los sistemas penales nacionales. A nivel europeo, este rol fundamental lo cumple la DIR 2014/42/UE en su doble faz de instrumento preventivo y restablecedor del equilibrio patrimonial modificado injustamente por los hechos delictivos. El panorama es completamente divergente en el ámbito iberoamericano, presidido por la heterogeneidad normativa -códigos penales, códigos de proceso penal, legislación especial por ámbitos delictivos, etc. - y la disparidad de soluciones acogidas para legitimar ataques al derecho constitucional a la propiedad, entre las que van ganando pujanza modalidades de extinción de dominio. de terceros en el Considerando n. 24 DIR 2014/42/UE. 
reforma de calado en esta materia por la $\mathrm{LO} 1 / 2015^{20}$, bajo las directrices armonizadoras vinculantes de la Unión Europea (art. 6 DIR 2014/42/ $\left.\mathrm{UE}^{21}\right)^{22}$. En el decomiso de bienes de terceros los órganos jurisdiccionales tienen entonces el deber de particularizar su actuación, basándose en hechos y circunstancias concretas ${ }^{23}$.

Estos breves párrafos pretender servir de justificación para la doble vertiente empleada a la hora de analizar el problema: (i) la base jurídica que permite operar el decomiso de bienes de terceros y (ii) las normas que rigen la intervención de estas personas en el proceso penal.

\section{DECOMISO DE BIENES DE TERCEROS}

El Preámbulo de la LO 1/2015 alude al «decomiso de bienes de terceros», como vía novedosa junto al «decomiso sin sentencia»y

20 Ley Orgánica 1/2015, de 30 de marzo, por la que se modifica la Ley Orgánica 10/1995, de 23 de noviembre, del Código Penal [BOE n. 77, de 31 de marzo de 2015].

21 El legislador patrio, más que sentirse vinculado por el mandato de este art. 6 DIR 2014/42/UE, lo ha estado por el art. 6 de la Propuesta de Directiva del Parlamento Europeo y del Consejo sobre el embargo preventivo y el decomiso de los productos de la delincuencia en la Unión Europea [COM(2012) 85 final] (PDIR 2014/42/UE), más amplio en su contenido y severidad con relación a los intereses jurídicos de los terceros.

22 Con relación a la influencia del Derecho supranacional e internacional en esta novedosa regulación española del decomiso, y de algunas de sus modalidades más controvertidas como el decomiso ampliado, el decomiso sin condena o el propio decomiso de bienes de terceros, vid. VIDALES RODRÍGUEZ, Catalina; PLANCHADELL GARGALLO, Andrea. Decomiso: Estudio de la normativa internacional y de la legislación española (Aspectos penales y procesales). Miami (Florida). Center for the Administration of Justice, p. 34 y ss., 2018; CARRILLO DEL TESO, Ana Elena. Decomiso y recuperación..., cit., p. 39 y ss.; RODRÍGUEZ-GARCÍA, Nicolás. Redescubrimiento de las bonanzas del decomiso en las tácticas supranacionales e internacionales para poner freno a la «sociedad incivil». BERDUGO GÓMEZ DE LA TORRE, Ignacio; FABIÁN CAPARRÓS, Eduardo Ángel; RODRÍGUEZ GARCÍA, Nicolás (coords.). Recuperación de activos y decomiso. Reflexiones desde los sistemas penales iberoamericanos. Valencia: Tirant lo Blanch, p. 317 y ss., 2017.

23 Art. 6.1 DIR 2014/42/UE. 
al «decomiso ampliado» ${ }^{24}$, en una nueva vuelta de tuerca a la hora de facilitar instrumentos legales que sean más eficaces en la recuperación de activos procedentes del delito y en la gestión económica del mismo. En este sentido, el legislador no hace más que profundizar en su intención de hacer más efectivo el instituto de decomiso, frente al abuso de las normas tuitivas del derecho de propiedad. Pero, más allá de las intenciones del legislador, es claro que los terceros son detentadores de derechos y libertades constitucionales, desde la propiedad a la presunción de inocencia, pasando por la tutela judicial efectiva, la garantía a un proceso justo $^{25}$ y el derecho a formular medios de impugnación ${ }^{26}$. La resolución de este tipo de dilemas pasará entonces, en gran medida, por dónde coloquemos los límites ${ }^{27}$ entre el interés por incrementar la eficacia, dar mayor seguridad jurídica y mejorar técnicamente la regulación del decomiso de bienes en poder de terceros, lo que a la postre viene a

24 Entre ellos, como destaca BOUCHT, podemos encontrar como punto de encuentro la difícil demostración de una conexión entre un hecho delictivo en particular y un activo patrimonial, y entre éstos y personas físicas y jurídicas distintas a las que han tenido relación con los ilícitos penales. Vid. BOUCHT, Johan. Extended Confiscation: Criminal Assets or Criminal Owners? In: LIGETI, Katalin; SIMONATO, Michele (edits.): Chasing Criminal Money. Challenges and Perspectives on Asset Recovery in the EU. London: Hart Publishing, p. 117 y ss., 2017.

De ahí que como destaca SÁNCHEZ SISCART, José Manuel. Intervención de terceros afectados por el decomiso y el decomiso autónomo. La recuperación y gestión de activos. Formación a Distancia, n. 3, p. 4, 2016, antes de que la Ley de Enjuiciamiento Criminal haya previsto expresamente el estatus procesal de los terceros que puedan ser objeto de decomiso ha tenido que ser la jurisprudencia la que haya tenido que colmar esa laguna legal fijando pautas para evitar la indefensión de esos sujetos y haciendo efectivos sus derechos y garantías procesales constitucionales. Sobre su contenido y alcance vid. PLANCHADELL GARGALLO, Andrea; VIDALES RODRÍGUEZ, Catalina. Decomiso: comentario crítico desde una perspectiva constitucional. Estudios Penales y Criminológicos, n. 38, p. 37 y ss., 2018.

Vid. STS de 25 de julio de 2017 (n. 602).

27 En opinión de AGUADO CORREA, «[p]ara el legislador los fines justifican los medios aun cuando con éstos se vulneren derechos fundamentales y principios constitucionales, y la eficacia está por encima de las garantías». Cfr. AGUADO CORREA, Teresa. Artículo 127 quater. In: GÓMEZ TOMILLO, Manuel. Comentarios prácticos al Código Penal. Parte General. Tomo I. Pamplona: Aranzadi, p. 1032, 2015. 
significar focalizar el trabajo de los operadores jurídicos en el concepto de disponibilidad ${ }^{28}$.

Veamos primero los cambios introducidos por el legislador en el Código Penal y las características dimanantes de ello:

a) Autonomía: este decomiso ha pasado de ser un apéndice a tener un artículo propio (art. 127 quater CP).

b) Equivalencia: la tutela de los terceros está ubicada al mismo nivel que algunas ${ }^{29}$ otras clases de decomiso ${ }^{30}$, sin que esté subordinado a la ineficacia aplicativa del decomiso directo o del decomiso por sustitución ${ }^{31}$, razón por la cual podemos catalogar al decomiso de bienes de tercero como autónomo ${ }^{32}$.

28 Sobre ello, y para el caso del Derecho italiano, vid. MAUGERI, Anna Maria. La trasposición de la Directiva 2014/42/UE en Italia. In: BERDUGO GÓMEZ DE LA TORRE, Ignacio: FABIÁN CAPARRÓS, Eduardo Ángel; RODRÍGUEZ-GARCÍA, Nicolás (edits.). Decomiso y recuperación de activos. Crime doesn't pay. Valencia: Tirant lo Blanch, 2020 - en prensa-.

29 Aunque el art. 127 quater.1 CP señala la posible aplicación por los jueces y tribunales de las clases de decomiso sobre bienes, efectos y ganancias «[...] a que se refieren los artículos anteriores» transferidos a terceras personas, no parece acertado incluir el decomiso autónomo del art. 127 ter $\mathrm{CP}$, en el que no se va a dictar sentencia en el proceso penal principal, supuesto que además solamente puede dirigirse contra quien haya sido formalmente acusado o contra el investigado con relación al que existan indicios racionales de criminalidad (art. 127 ter.2 CP).

30 En el art. 127 quater 1 CP se utiliza el adverbio «también» al atribuir la facultad a los jueces y tribunales para que puedan acordarlo, indicando la igualdad de este decomiso de bienes de terceros con el decomiso directo, con el decomiso por sustitución y el decomiso ampliado, estrategia punitiva que para AGUADO CORREA puede implicar la vulneración del derecho a la propiedad del tercero y del principio de proporcionalidad. Cfr. AGUADO CORREA, Teresa. Artículo 127..., cit., p. 1033.

31 O inclusive como una alternativa a los mismos, como se posibilita en el Considerando n. 25 DIR 2014/42/UE: «Los Estados miembros tienen la facultad de considerar el decomiso de los bienes de un tercero como medida subsidiaria o alternativa al decomiso directo, según proceda de conformidad con el Derecho nacional».

32 GONZÁLEZ CANO, María Isabel. El decomiso como instrumento de la cooperación judicial en la Unión Europea y su incorporación al proceso penal español. Valencia: Tirant lo Blanch, p. 115, 2016. 
c) Amplitud subjetiva: debido a que en «terceras personas» debemos entender incluidas tanto a personas físicas como a jurídicas -a las que se deberá aplicar la teoría del levantamiento del velo ${ }^{33}$ en la búsqueda del titular real ${ }^{34}$-; éstas pueden ser sujeto pasivo de un proceso penal, desde la LO 5/2010, en condiciones de igualdad con las personas físicas, quienes además son las que realmente actúan amparadas en esa estructura jurídica de las empresas.

d) Amplitud objetiva: más extenso, dado que si por cualquier circunstancia no se pueden decomisar los bienes, efectos y ganancias transferidos a un tercero, lo serán bienes de éste por un valor equivalente a los mismos ${ }^{35}$.

e) Carácter potestativo: en el momento de ser impuesto por los órganos jurisdiccionales ${ }^{36}$, dejando atrás veinte años donde el decomiso de bienes de terceros ha sido obligatorio, sin ninguna excepción, lo que impedía cualquier tipo de ponderación por parte de los juzgados y tribunales al apreciar las circunstancias concurrentes y las alegaciones defensivas que pudiera esgrimir ese tercero, si es que se le daba graciosamente audiencia en las actuaciones judiciales, participación que no estaba prevista normativamente.

f) Carácter sospechoso: que subyace en toda la regulación de las «terceras personas» relacionadas con los bienes a decomisar, en la que ni en una sola ocasión se verbaliza el principio general del Derecho de la

33 Vid. MARTÍN PÉREZ, José Antonio. El comiso de bienes de propiedad de 'tercero': Análisis del respeto de las reglas sobre titularidad por las sentencias penales (A propósito del Auto TC 125/2004, de 19 de abril). Derecho Privado y Constitución, n. 205, p. 228 y ss., 2005; OCAÑA RODRÍGUEZ, Antonio. Medidas cautelares reales..., cit., p. 217 y ss. Como se destaca en la STS de 2 de junio de 2015 (n. 338), ésta es una teoría que encuentra su apoyo en instituciones como el fraude a la ley, el abuso del derecho o la buena fe, y que sirve para eliminar la ficticia estructura societaria y descubrir la realidad patrimonial del verdadero titular de los bienes.

${ }^{34}$ Sin que importe dónde pueda estar el administrador formal de la empresa, como advierte CHOCLÁN MONTALVO, José Antonio. El patrimonio criminal. Comiso y pérdida de la ganancia. Madrid: Dykinson, p. 37, 2001.

35 También así se prevé en el art. el art. 6.1 DIR 2014/42/UE.

36 «[...] [P]odrán acordar», se recoge literalmente en el art. 127 quater 1 CP. 
bona fides ${ }^{37}$, es decir, su posible condición como «terceros de buena fe», como se hacía en las versiones anteriores del art. $127 \mathrm{CP}^{38}$.

La tendencia a maximizar la aplicación del instituto se expresa de manera palmaria en el relajamiento del principio de buena fe. En efecto, el art. 127 quater $1 \mathrm{CP}$ desprotege la posición jurídica de las terceras personas que hayan recibido la transferencia de bienes, efectos y ganancias - 0 de su valor equivalente-, en dos situaciones, diferenciadas por el objeto sobre el que va a recaer el decomiso:

a) En primer término, cuando se trate de efectos y ganancias, si los terceros los hubieran adquirido con conocimiento de que proceden de una actividad ilícita, o cuando una persona diligente habría tenido motivos para sospechar, en las circunstancias del caso, de su origen ilícito $^{39}$. En este supuesto el legislador recurre a tres estados subjetivos relacionados con la conducta de la tercera persona -la adquisición-, que le hace acreedor de una consecuencia jurídica por su actuación conocida, querida y buscada - la pérdida de efectos y ganancias-: «con conocimiento», «persona diligente»y «sospecha» ${ }^{40}$.

b) En segundo lugar, en el caso de otros bienes, cuando los hubieran adquirido con conocimiento de que de este modo se dificultaba

37 Disciplinado con carácter general en los arts. 433 a 435 CC.

38 Por el contrario, en el art. 6.1 DIR 2014/42/UE se puede leer como la regulación de bienes de terceros «[...] no perjudicará los derechos de terceros de buena fe».

39 Vid. ROIG TORRES, Margarita. El comiso como estrategia frente a la corrupción en Alemania: interpretación jurisprudencial. Estudios Penales y Criminológicos, n. extra 38, p. 560 y ss., 2018, quien al contraponer la regulación nacional del decomiso de terceros con la alemana deja planteadas dudas de constitucionalidad por los excesos de la norma española. Además vid. CARRILLO DEL TESO, Ana Elena. El nuevo régimen de recuperación de activos en Alemania o la sublimación del principio crime doesn't pay. In: BERDUGO GÓMEZ DE LA TORRE, Ignacio: FABIÁN CAPARRÓS, Eduardo Ángel; RODRÍGUEZ-GARCÍA, Nicolás (edits.). Decomiso y recuperación de activos. Crime doesn't pay. Valencia: Tirant lo Blanch, 2020 - en prensa-.

40 Vid. GONZÁLEZ CANO, María Isabel. El decomiso..., cit., p. 116 y ss., quien con todo acierto plantea la conexión de estas exigencias del art. 127 quater 1 $\mathrm{CP}$ con los requisitos que tienen que concurrir para que la actuación del tercero pueda derivar en su imputación por blanqueo de capitales (art. 3010.1 CP) o por receptación (art. 298.1 CP), delitos por los que hasta ese momento no estaba siendo investigado. 
su decomiso, o cuando una persona diligente habría tenido motivos para sospechar, en las circunstancias del caso, que de ese modo se dificultaba su decomiso. Ahora, lo relevante no es ya el origen -ilícito- de los bienes sino el saber que con su actitud el tercero impide, en todo o en parte, la eficacia del decomiso.

En ambos supuestos se castiga al tercero por su dolo - con conocimiento- o negligencia ${ }^{41}$ - no ha sido una persona diligente que sospeche- con la pérdida de los bienes decomisados que fueron en su día del penado. Sin embargo, y dispuesto a allanar la dificultad probatoria que estas cláusulas suponen, el legislador se ha decantado, una vez más, $\mathrm{y}$ al igual que hace con el condenado en el decomiso ampliado de sus bienes, por alterar las reglas del juego acusatorio: será el tercero el que tenga que cuestionar que no ha conocido o que no ha tenido motivos para sospechar que se trataba de bienes procedentes de una actividad ilícita, o que le eran transferidos para evitar su decomiso. Y ello en especial cuando los bienes o efectos, siendo de comercio legal, le hubieran sido transferidos a título gratuito o por un precio inferior al real de mercado, en el único supuesto de que los mismos fueran de comercio legal. En estas dos situaciones, el art. 127 quater 2 in fine CP presume que su adquisición por el tercero ha sido ilegítima ${ }^{42}$.

La construcción de esta presunción iuris tantum amerita algunos señalamientos ${ }^{43}$ :

41 GONZÁLEZ-CUÉLLAR SERRANO, Nicolás. Aspectos procesales del decomiso: intervención de terceros afectados por el decomiso, el proceso de decomiso autónomo y la Oficina de Recuperación y Gestión de Activos. In: MARCHENA GÓMEZ, Manuel; GONZÁLEZ-CUÉLLAR SERRANO, Nicolás. La reforma de la Ley de Enjuiciamiento Criminal en 2015. Madrid: Castillo de Luna, p. 446, 2016, hace equivaler «culpa leve» a la «buena fe» para eximir en esos casos de responsabilidad penal al tercero.

42 Un planteamiento inverso al seguido en el ordenamiento jurídico alemán, en el que como apunta ROIG TORRES, Margarita. El comiso..., cit., p. 577-578, se parte de la idea de que el decomiso no se debe practicar cuando se está ante un tercero de buena fe, lo que acontece cuando estamos ante una persona que adquiere el elemento patrimonial delictivo mediante un negocio oneroso.

43 Donde el comportamiento esperable del tercero, más que diligente, parece suspicaz. Sobre el punto, vid. CARRILLO DEL TESO, Ana Elena. Consideraciones sobre la actividad probatoria en torno a la delincuencia económica. Justicia: Revista de Derecho Procesal, n. 2, p. 524 y ss., 2019; HAVA GARCÍA, 
a) El uso del término «transferir», y no «adquirir» - sobre el cual no hay dudas de quien la realiza-, sin identificar el sujeto activo ${ }^{44}$, lo cual tiene en algunos casos una particular relevancia, en especial cuando se trata de personas jurídicas ${ }^{45}$.

b) Nada indica con relación al momento en el cual se ha llevado a cabo la transferencia de los bienes, efectos y ganancias, que puede ser coetánea a la celebración del proceso penal principal contra el titular originario de los mismos, como también anterior, dónde más alejamiento temporal implica mayores posibilidades de que el tercero desconociera su origen ilícito.

c) Cabe estimar que el instituto no se limita a los bienes, efectos y ganancias, sino a su «mezcla» o «transformación», tanto cuando el decomiso sea directo, por sustitución o ampliado, como también cuando las operaciones se realicen para favorecer la propia transferencia y la ocultación de las responsabilidades.

Esther. La nueva regulación del comiso». In: QUINTERO OLIVARES, Gonzalo (coord.). Comentarios a la reforma penal de 2015. Pamplona: Aranzadi, p. 222, 2015. Y en general, sobre esta tipología de presunciones, vid. DURÁN SILVA, Carmen. Las presunciones legales iuris tantum en la figura del decomiso». Revista General de Derecho Procesal, n. 48, p. 15 y ss., 2019.

44 Es lógico pensar que usualmente será el condenado penal, con lo cual la transmisión es directa. Sin embargo, no será infrecuente que tal y como acontece con el lavado de activos, la transmisión de los bienes entre el condenado penal y el tercero sea indirecta, en un intento por distanciar los bienes de su origen delictivo con la intervención de testaferros, sociedades pantalla, etc., lo que demandará una investigación patrimonial de calado para localizar el destinatario final de los bienes sobre el cual actuar y probar su conducta maliciosa que legitime la intervención y pérdida de los mismos. Esta realidad puede valerle al tercero de cobertura para alegar su desconocimiento y ausencia de sospechas con relación a la procedencia de los bienes, puesto que su deber de diligencia no debe significar que ese tercero quede compelido a hacer su propia investigación patrimonial sobre el tracto seguido por los bienes. Con relación a las implicaciones probatorias para las acusaciones con relación a este elemento de la transmisión, vid. CAMPOS NAVAS, Daniel. Otras modalidades de decomiso: el decomiso ampliado, el decomiso de bienes de tercero y el decomiso sin sentencia condenatoria. In: VV.AA. El decomiso: aspectos sustantivos y procesales. Madrid: Centro de Estudios Jurídicos, p. 16 y ss., 2019; MARTÍN SAGRADO, Óscar. El decomiso de las sociedades pantalla. Diario La Ley, n. 8768, p. 1 y ss., 2016.

45 SSTS de 29 de julio de 2002 (n. 867); de 19 de septiembre de 2019 (n. 422). 
d) La referencia a un «precio inferior al real de mercado» ha merecido ya apropiadas objeciones lingüísticas ${ }^{46}$. De otro lado, no se ha precisado si el precio alude al momento de comisión del delito o al de adquisición, ni cómo establecer el precio de mercado. En lo sustancial, se echa en falta que no haya incluido un parámetro de proporcionalidad, utilizando el adverbio «significativamente», tal y como hace el europeo ${ }^{47}$.

e) Es evidente que el dispositivo busca generar un efecto preventivo general, como parte de una estrategia de política criminal ${ }^{48}$. Llama la atención, por ello, que el precepto no incluya ni una mención

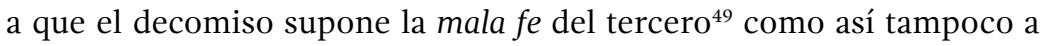

46 Se podría haber copiado la expresión usada por la Unión Europea en el art. 6.1 DIR 2014/42/UE: «[...] la transferencia o adquisición se haya realizado... a cambio de un importe... inferior a su valor de mercado». Por ejemplo, en el caso de Portugal, como estudia ANTUNES, Maria João. Recuperación de activos. Garantías procesales del decomiso de bienes en el Derecho portugués. In: BERDUGO GÓMEZ DE LA TORRE, Ignacio: FABIÁN CAPARRÓS, Eduardo Ángel; RODRÍGUEZ-GARCÍA, Nicolás (edits.). Decomiso y recuperación de activos. Crime doesn't pay. Valencia: Tirant lo Blanch, 2020 - en prensa-, en la legislación contra la criminalidad organizada y económica financiera se utiliza como presupuesto del decomiso la trasmisión a terceros de bienes a cambio de una «contraprestación irrisoria».

En el art. 6.1 DIR 2014/42/UE, introducido en la tramitación legislativa, por cuanto el mismo no se contenía en 2012 en el art. 6.2.b) PDIR 2014/42/UE.

En general, aleccionar al penado, al tercero y a la colectividad sobre lo ilegal de su conducta. Un reproche penal con consecuencias patrimoniales: finiquitar su enriquecimiento ilegítimo, porque en los supuestos recogidos en el Código Penal ha adquirido los bienes de forma gratuita, o con una rebaja sustancial en el precio de los mismos. Vid. NIEVA FENOLL, Jordi. El procedimiento de decomiso autónomo. En especial, sus problemas probatorios. Diario La Ley, n. 8601, p. 3, 2015, que caracteriza de «civil» la naturaleza jurídica del decomiso de los bienes de un tercero.

Comportamiento que encuentra reproche en el Código Penal y que debiera determinar que el juez o tribunal dé tanto de culpa para que se determine su alcance y eventual responsabilidad penal por blanqueo -doloso o imprudente-, receptación civil - cuando los adquiera con absoluto desconocimiento del origen ilícito-, simulación de contrato, alzamiento de bienes, encubrimiento, etc., puesto que en caso de no hacerse además de ser intolerable la dejación de la legalidad penal en el Estado de Derecho por una complacencia - e incluso conveniencia- mal entendida de los operadores jurídicos se estaría generando desde las propias salas de los tribunales un grave foco de impunidad, contrario a los efectos de prevención general buscados. AGUADO CORREA ya puso de manifiesto antes de la aprobación de la LO 1/2015 como 
la forma de regularización de la situación jurídica de esos bienes con relación a los terceros, y a los - eventuales- terceros de los terceros ${ }^{50}$.

\section{INTERVENCIÓN DE TERCEROS EN EL PROCESO PENAL}

La posibilidad de que un tercero intervenga en el proceso penal radica en que pueda ser considerado poseedor de un derecho puesto en crisis por el instituto de decomiso. En este sentido, se entiende por tercero de buena fe a toda persona que ha consolidado su derecho sobre un bien mediante un acto legítimo de adquisición, ignorando que en su título concurre un vicio que pueda invalidarlo. Esta delimitación excluye

«[...] a través de este precepto lo que se permite es acordar el comiso sobre los bienes de sujetos que son responsables de un delito de blanqueo de capitales, doloso o imprudente, sin necesidad de iniciar un proceso penal con el fin de declarar la responsabilidad criminal de los mismos, por la vía de considerarlos «terceros» a efectos del decomiso», idea en la que persiste VIDALES RODRÍGUEZ, aludiendo a que una vez incautados los bienes puede decaer el interés por la represión del eventual delito cometido. Y GASCÓN INCHAUSTI señala como «[...] los contornos imprecisos y difuminados de la figura del 'tercero que puede resultar afectado por el decomiso' ofrecen cabida a una estrategia de política criminal encaminada a lograr el máximo decomiso con el mínimo esfuerzo (procesal) posible: si se da prioridad al decomiso frente al castigo penal en sentido estricto - en especial cuando hay personas jurídicas involucradas-, tanto el Juez de Instrucción como la Fiscalía pueden considerar más hacedero enfrentarse a un sujeto atribuyéndole la condición de tercero que la de encausado o partícipe a título lucrativo». Cfr. GASCÓN INCHAUSTI, Fernando. Las nuevas herramientas procesales para articular la política criminal de decomiso total: La intervención en el proceso penal de terceros afectados por el decomiso y el proceso para el decomiso autónomo de los bienes y productos del delito. Revista General de Derecho Procesal, n. 38, p. 14, 2016; VIDALES RODRÍGUEZ, Catalina. Consecuencias accesorias: Decomiso (arts. 127 a 127 octies). In: GONZÁLEZ CUSSAC, José Luis (dir.). Comentarios a la Reforma del Código Penal de 2015. Valencia: Tirant lo Blanch, p. 403, 2015; AGUADO CORREA, Teresa. Comiso: crónica de una reforma anunciada. Análisis de la propuesta de Directiva sobre embargo y decomiso de 2012 y del Proyecto de reforma del Código Penal de 2013. InDret: Revista para el Análisis del Derecho, n. 1, p. 49 y 50, 2014.

50 Toda vez que se ordena el decomiso de manera directa, e implícitamente, sin juzgarlo civilmente - por ser ilegal la causa del contrato- la nulidad de los acuerdos de transmisión del - ahora - penado con los terceros, y la transferencia de los bienes, no al anterior titular — el condenado penal-, sino directamente al Estado. 
$a b$ initio que pueda ser considerado con expectativas de defender ese derecho en un proceso penal a aquella persona que aparece como titular administrativo o registral de un bien ${ }^{51}$.

La Ley de Enjuiciamiento Criminal ${ }^{52}$, formalizando la práctica seguida por los órganos jurisdiccionales ${ }^{53}$, que ha sido proclive a dar cobertura en las acciones confiscatorias estatales -máxime desde que posible legalmente imputar a personas jurídicas ${ }^{54}$ - despeja las dudas sobre si se pueden personar y cómo pueden intervenir en los procesos penales terceras personas para defender su propiedad ${ }^{55}$, cuando sus derechos e intereses puedan resultar afectados por una resolución judicial de decomiso, aspecto que, como hemos dicho, no fue una novedad introducida por el legislador de 2015. Y no se hace en el Código Penal, que se limita a establecer cuándo, cómo, por qué y por quién se puede producir la pérdida de bienes, efectos y ganancias de terceras personas. Una elección del cuerpo normativo procesal básico correcta, mantenida en el tiempo,

51 Vid. STS de 11 de abril de 2016 (n. 296).

52 Capítulo I («De la intervención en el proceso penal de los terceros que puedan resultar afectados por el decomiso»), del Título III ter («De la intervención de terceros afectados por el decomiso y del procedimiento de decomiso autónomo») del Libro IV («De los procedimientos especiales») de la Ley de Enjuiciamiento Criminal.

53 Vid. SSTS de 20 de enero de 1997 (n. 56); de 29 de julio de 2002 (n. 867). Más recientemente, en la STS de 2 de junio de 2015 (n. 338) se establece como «[...] en todo juicio penal debe agotarse los medios para conseguir que el acusado y el responsable civil o personas afectadas por cualquier pronunciamiento de esta índole - en este caso el comiso- sean llamados al proceso para que tengan opción de defenderse, alegando lo que estimen conveniente y aportando las pruebas de que intenten valerse. Por ello, deben agotarse previamente todas las modalidades de citación de unas garantías y debe existir constancia formal de haberse practicado éstas o en su caso haberse intentado y además debe hallarse fundada en criterios de razonabilidad, que lleven a la convicción o certeza de la inutilidad de aquellos otros medios de comunicación». Más ampliamente sobre pronunciamientos jurisdiccionales en esta materia, en particular para poner coto a las actuaciones de los testaferros, vid. CARRILLO DEL TESO, Ana Elena. Decomiso y recuperación..., cit., p. 209 y ss.

54 STS de 29 de julio de 2002 (n. 867). Vid. GONZÁLEZ CANO, María Isabel. El decomiso..., cit., p . 119 y ss., 2016.

55 STS de 25 de julio de 2017 (n. 602). 
complemento necesario de la modificación penal ${ }^{56}$, pero sobre la que se puede discutir el trámite parlamentario seguido, y el tiempo empleado, hasta regular esta materia en los artículos 803 ter a y siguientes LECR.

Ni en el Anteproyecto de reforma del Código Penal de 2012, ni el de 2013, encontramos en las Disposiciones Finales alusión alguna a la intervención en el proceso penal de terceras personas afectadas por el decomiso. Sin embargo, en la Disposición Final Segunda Noveno del Proyecto de Ley de reforma del Código Penal de 2013 se creó, dentro del nuevo Título VIII del Libro IV, un «Capítulo I» con la rúbrica «De la intervención en el proceso penal de los terceros que puedan resultar afectados por el comiso», en el que quedaban integrados los nuevos artículos 846 bis a) a 846 bis d) CP, que eran objeto de articulación en las cuatro siguientes disposiciones finales.

Sin mayor explicación, en 2015, y estando muy avanzada la tramitación parlamentaria de este Proyecto de reforma del Código Penal, se presentó en el Congreso de los Diputados el Proyecto de Ley de modificación de la Ley de Enjuiciamiento Criminal para la agilización de la justicia penal y el fortalecimiento de las garantías procesales, cuyo Artículo Único Ocho hacía suya la propuesta de introducir un nuevo Título III ter a la Ley de Enjuiciamiento Criminal, con lo cual fue retirada esta materia de la reforma penal que se seguía en el Senado. Un cambio

56 En el Preámbulo de la Ley 41/2015, de 5 de octubre, de modificación de la Ley de Enjuiciamiento Criminal para la agilización de la justicia penal y el fortalecimiento de las garantías procesales [BOE n. 239, de 6 de octubre de 2015], se reconoce como la reforma procesal en materia de decomiso «[...] ha de ponerse en contexto con las modificaciones del decomiso que por su parte introduce la reforma del Código Penal, y en concreto, como complemento de aquella, se ha previsto ahora la intervención en el procedimiento de los terceros que puedan verse afectados por el decomiso. Sus derechos se garantizan no solo en este procedimiento, sino con la articulación de un recurso de anulación, por remisión nuevamente a la Ley de Enjuiciamiento Civil, en caso de que la resolución se haya dictado sin considerar su condición de interesado en la causa». Más allá de esta inicial justificación teórica, la puesta en práctica de los nuevos preceptos - penales y procesales- reguladores del decomiso de terceros ha puesto de manifiesto, como enfatiza CONDE FUENTES, Jesús. La intervención en el proceso penal de terceros afectados por el decomiso. Revista Penal, n. 42, p. 65, 2018, contradicciones, solapamientos y errores técnicos que lastran notablemente su adecuada aplicación por los operadores jurídicos. 
sobrevenido, inesperado y quizá improvisado ${ }^{57}$, que ha sido criticado por dar lugar a un «exceso por retraso» que redunda negativamente en la seguridad jurídica y en el respeto a los derechos fundamentales de los terceros afectados por el decomiso ${ }^{58}$ en los cinco meses de desfase por la entrada en vigor de la reforma procesal con relación a la reforma penal ${ }^{59}$.

Analizaremos a continuación la normativa vinculada a la intervención de terceras personas en el proceso penal español, a través de algunos rasgos concretos:

a) Sujeto pasivo: Tanto en el rótulo del Título y del Capítulo, como en el comienzo del art. 803 ter a LECR, el legislador ha acogido la terminología europea para referirse al sujeto al cual se le abre el cauce de participación en un proceso penal, en la cual se utilizan dos términos concretos: (i) tercero, y por lo tanto no personado en las actuaciones orientadas a dirimir la responsabilidad penal por los hechos delictivos; y, además, (ii) restringida sólo a aquellos que puedan resultar afectados por el decomiso. Partiendo de ellos, en la cuestión trascendental de la identificación de los terceros afectados —directa o indirectamente-por el decomiso y que tienen que ser llamadas al procedimiento, en el que más adelante se discutirá y resolverá sobre una eventual mala fe en su

57 De hecho, nada presagiaba que esta fuera a ser la estrategia legislativa a seguir por cuanto el Artículo único Diecinueve del Anteproyecto de Ley Orgánica de modificación de la Ley de Enjuiciamiento Criminal para la agilización de la justicia penal, el fortalecimiento de las garantías procesales y la regulación de las medidas de investigación tecnológicas, de 5 de diciembre de 2014 , nada hablaba de esta intervención de terceros afectados por el decomiso en el proceso penal principal, ya que el Título III ter propuesto tenía como único contenido la regulación del procedimiento de decomiso autónomo.

AGUADO CORREA, Teresa. Artículo 127 quater. In: GÓMEZ TOMILLO, M.: Comentarios prácticos al Código Penal. Parte General. Tomo I. Pamplona: Aranzadi, p. 1032, 2015.

59 Además, en la Disposición Transitoria Única Ley 41/2015 se establece que esta reforma legal «[...] se aplicará a los procedimientos penales incoados con posterioridad a su entrada en vigor». Con relación al régimen transitorio de esta reforma, entrada en vigor el 6 de diciembre de 2015, vid. GONZÁLEZ-CUÉLLAR SERRANO, Nicolás. Aspectos procesales..., cit., p. 518 y ss.; JIMÉNEZ-VILLAREJO FERNÁNDEZ, Francisco. La nueva regulación del decomiso y la recuperación de activos delictivos en el ordenamiento jurídico español. Revista del Ministerio Fiscal, n. 0, p. 121 y ss., 2015. 
relación con los bienes decomisados ${ }^{60}$, el art. 803 ter a.1 LECR señala, en primer lugar, a aquellas personas -físicas o jurídicas, según nuestro criterio- distintas del investigado o encausado a quien pertenezca el bien cuyo decomiso se solicita ${ }^{61}$. La relación con el bien se limita al derecho de propiedad, en este primer caso, pues las personas que vean afectado el derecho de uso y disfrute de los bienes por el decomiso encuentran cobertura jurídica en el siguiente apartado del artículo. El decomiso del bien o de los bienes no puede disponerse de oficio, sino que tiene que ser solicitado por el Ministerio Fiscal o por otra parte acusadora personada en autos.

b) Derechos del sujeto pasivo: La Ley de Enjuiciamiento Criminal brinda a estar personas el mismo tipo de protección. En general, el derecho constitucional de tutela judicial efectiva, con derecho a la defensa y a un proceso justo. En particular, el resguardo de los principios de audiencia y contradicción, y a contar desde el inicio con un letrado de su confianza -de oficio o de libre designación- para que desarrolle la defensa en los términos que estime pertinentes.

c) Oportunidad de intervención en el proceso: El art. 803 ter a LECR, rotulado «Resolución judicial de llamada al proceso», nada dice sobre la oportunidad en que debe ser acordada la intervención judicial, siendo que este momento es esencial para el correcto y pleno ejercicio del derecho de defensa. Esencial, cuanto menos, para que antes de la sentencia de decomiso el órgano judicial tome en cuenta eventuales alegaciones del tercero. Entre otros aspectos: (i) el de alegar su condición de adquirente de buena fe, conforme a los parámetros del art. 127 quater CP; (ii) el de obtener una indemnización por los daños y perjuicios provocados sobre su patrimonio, en caso de operarse el decomiso; y (iii) el de demostrar

60 Vid. BUJOSA VADELL, Lorenzo Mateo. La perspectiva procesal del decomiso. In: CASTILLEJO MANZANARES, Raquel (dir.). El nuevo proceso penal sin Código Procesal Penal. Barcelona: Atelier, p. 710-711, 2019, con quien compartimos el criterio de maximizar la llamada al proceso de los terceros para que en el ejercicio a su derecho a la tutela judicial efectiva puedan ser oídos y se puedan defender, inclusive proponiendo prueba para rebatir las presunciones que en la norma penal se contienen.

${ }^{61}$ En este sentido $c f r$. GASCÓN INCHAUSTI, Fernando. Las nuevas herramientas..., cit., p. 17. 
su ajenidad respecto de las conductas fraudulentas u obstruccionistas del imputado, a raíz de la transferencia de los bienes.

Cabe tener presente que durante todo el trámite del procedimiento penal se pueden dictar resoluciones judiciales que afecten directamente los derechos de terceros. Pensemos en medidas cautelares $-v$. gr., el embargo-, en el decomiso provisional, en el uso provisional de los bienes o en la destrucción de los mismos. Antes de pronunciar cualquiera de ellas, el tercero tiene que ser oído por el órgano judicial actuante, siendo nula de pleno Derecho toda resolución que se dicte sin dar a esa tercera persona la posibilidad real y efectiva de defenderse. En cualquiera de las situaciones, no hay que desconocer que para que sea legal el decomiso de bienes de terceros éste tiene que haber sido oído, cuando menos en el juicio oral, antes de ser tomada una decisión de este calado para sus intereses jurídicos. De no hacerlo, se le reconoce el derecho a pedir la rescisión de la sentencia por afectar la misma a sus bienes, derechos o situación jurídica (art. 803 ter d.1.I LECR), puesto que se habrá acordado el decomiso sin darle la oportunidad de oponerse al mismo, por desconocer su existencia (art. 803 ter d.2 LECR) ${ }^{62}$.

d) Forma de acordar el derecho a la intervención: Sabemos que la llamada al proceso, como cualquier otra actuación procesal, es de la exclusiva responsabilidad del juzgado o tribunal que, en ese momento concreto, esté conociendo del asunto. Por tanto, habrá que aplicar las normas generales de competencia objetiva y funcional, pudiendo ser tomada, como hemos señalado, tanto en la fase de investigación como en la vista pública. Es una decisión judicial particularizada en cada caso, en función de las circunstancias concurrentes relativas a los bienes, a los sujetos y a sus relaciones jurídicas y fácticas previas. Ahora bien, para llegar a ese punto, el órgano jurisdiccional podrá estar actuando de oficio, pero también el art. 803 ter a.1 LECR permite que sean las partes

62 Como bien señala GASCÓN INCHAUSTI, esta previsión sirve de cláusula de cierre general, al dar cabida tanto a los casos en que se produjo la llamada al proceso, pero no fue eficaz por motivos diversos a los previstos en el art. 501 LEC, como a aquellos otros en los que la llamada no tuvo lugar, tanto si la cuestión se planteó, pero no se decidió - erróneamente- que no era procedente, como si ni siquiera llegó a plantearse la existencia del tercero afectado por el decomiso. Cfr. GASCÓN INCHAUSTI, Fernando. Las nuevas herramientas..., cit., p. 26. 
personadas quienes le insten la toma de esa decisión. Y tanto las activas como las pasivas, referidas a la responsabilidad penal como a la civil, ya que todas ellas estarán interesadas no tanto en preservar los derechos de los terceros como en que con posterioridad no se anulen las resoluciones tomadas sin audiencia previa, con lo cual se habrán generado gastos, dilaciones y riesgos para la ejecución adecuada del decomiso. Va de suyo que el propio tercero, siendo el más interesado, puede acudir al proceso, una vez tomado conocimiento de su existencia.

e) Requisitos de admisibilidad: Cuando el juez o tribunal actúe de oficio, en función de la primera opción del art. 803 ter a.1 LECR, será porque estima adecuada la llamada del tercero al proceso penal, lo cual presupone un análisis y control positivo de las circunstancias concretas que hacen a su admisibilidad.

El Ministerio Fiscal - a resultas de la investigación patrimonial llevada a cabo, junto a la Policía y demás unidades técnicas que colaboren con el mismo-, las acusaciones - con sus indagaciones propias-, la víctima - cuando no sea parte, y a la cual se le requiere su colaboración-, el encausado - de quien se presume su previa actuación fraudulenta- o el mismo tercero - el mejor posicionado-, pueden instar al tribunal, tal y como hemos dicho, a la citación del tercero al proceso. De este modo, y cualquiera sea la vía, corresponde al juzgado o tribunal el control de los requisitos de admisibilidad: (i) los elementos subjetivos, relacionados con la persona, esto es, la condición de tercero, en cualquiera de las dos categorías del art. 803 ter a.1 LECR, en función de su titularidad del bien u ostentación de un derecho distinto sobre el mismo; y (ii) los elementos objetivos, relacionados con los bienes, efectos y ganancias, que tienen que ser producto del delito y que tienen que haber pertenecido al encausado. Cuando este doble juicio valorativo haga acreedor al tercero de su llamada al proceso, efectuado sobre apreciaciones, sospechas e indicios no totalmente concluyentes, se tendrá que llevar a efecto su citación. Y no hacerlo, no es garantía de que no lo vaya a hacer con posterioridad, o que lo acuerde otro órgano jurisdiccional -el de enjuiciamiento, si se estaba en la fase de investigación-, o que al final se le sancione con el decomiso de sus bienes.

f) Revocabilidad: La llamada del tercero al proceso es revocable, si a la luz del desarrollo de las diligencias los condicionantes objetivos o 
subjetivos que la han motivado desaparecen. Lo mismo en la situación inversa: si el juzgado o tribunal no apreció — de oficio- la necesidad de llamar a las actuaciones al tercero, o si, incluso, denegó la petición que le hubiera podido efectuar en este sentido alguno de los sujetos legitimados, nada impide que por cualquiera de las dos vías - de oficio, o a instancia de parte - avanzada la tramitación procesal del litigio, pueda acordar la citación del tercero a las mismas.

g) Facultad de negarse a declarar: De conformidad con el art. 803 ter a.5 LECR, en caso de que se acuerde la participación del afectado por el decomiso en el proceso penal, antes de tomársele declaración se le informará de las situaciones previstas en el art. 416 LECR y que exime a los incursos en ellas de la obligación de declarar. Y es que el tercero puede ser eventualmente responsabilizado no sólo con la pérdida de su patrimonio, sino con una sanción penal, en caso de haber participado en la actividad fraudulenta u obstruccionista del autor del delito. El tercero no es parte en sentido estricto, desde el inicio de las actuaciones, como sí lo son el encausado o el investigado, pero a partir de su llamada y entrada en el proceso, y más allá de la denominación que se le dé63, se le deben reconocer y respetar los derechos procesales que las partes pasivas del proceso penal tienen, tanto las defensivas $-v$. gr., pudiendo guardar silencio, no estando obligado a declarar contra sí mismo ${ }^{64}-$, las alegatorias $-v$. gr., la última palabra a la finalización de las sesiones del

63 Como señala RAMOS MÉNDEZ, una vez que los terceros son llamados por el órgano jurisdiccional competente para tramitar el procedimiento y se les da intervención, «[...] su postura de tercería se resuelve en la condición de parte. A partir de dicho momento, la situación transitoria se ha transformado en la postura típica de parte». Cfr. RAMOS MÉNDEZ, Francisco. El sistema procesal español (9. ${ }^{\mathrm{a}}$ ed.). Barcelona: Atelier, 2013, p. 95.

64 Recordar como el art. 7 DIR 2016/343/UE fija para los Estados miembros la obligación de garantizar que los sospechosos o acusados tengan derecho a guardar silencio en relación con la infracción penal de que sean sospechosos o se les acuse. De igual forma, estas mismas personas tendrán derecho a no declarar contra sí mismos, lo que no tiene que impedir a las autoridades competentes recabar las pruebas que puedan obtenerse legalmente mediante el ejercicio legítimo de poderes coercitivos y que tengan una existencia independiente de la voluntad de los sospechosos o acusados. En definitiva, un derecho de acusados y sospechosos que cuando hagan uso de los mismos no podrá ser utilizado en su contra ni se considerará prueba de haber cometido la infracción penal de que se trate. 
juicio oral-, así como las probatorias - restringidas a todo lo que afecte al eventual decomiso de sus bienes-; inclusive, premiando su actitud colaboradora en la depuración de las responsabilidades ${ }^{65}$. Con ello, se reforzaría su estatuto jurídico marcado genéricamente con los derechos a la tutela judicial efectiva, al juicio justo y a la defensa técnica por un abogado en todas las actuaciones.

h) Aplicación estricta de las regulaciones atinentes al proceso penal: Los preceptos no aluden a ningún recaudo específico respecto de la comunicación de la llamada al proceso del tercero, como por ejemplo sí se hace en el desarrollo del procedimiento autónomo de decomiso, en el que son de aplicación las normas del enjuiciamiento civil. Una razón más para afianzar el entendimiento del carácter penal de esta entrada en el proceso de los terceros afectados. Siendo así las cosas, la regulación de las notificaciones, citaciones y emplazamientos de los arts. 166 y ss. LECR serán, en este trámite, de aplicación. A este reenvío a la normativa general sobre actos de comunicación en el proceso penal se refiere el art. 803 ter b.3.I LECR, en el que únicamente se hace alusión a que en la citación habrá que apercibir expresamente al afectado por el decomiso de que el juicio podrá ser celebrado en su ausencia, y que en el mismo podrá resolverse, en todo caso, sobre el decomiso solicitado.

i) Intervención facultativa: La intervención del tercero en el proceso penal está categorizada como un derecho procesal, del que puede o no hacer uso, o, incluso del que, habiéndolo ejercido, puede renunciar. Por ello, cuando el afectado puede comunicarle al órgano jurisdiccional su no oposición al decomiso, lo que va a determinar, bien que no se acuerde su intervención en el procedimiento, bien, cuando ya hubiera sido acordada, el cese de la misma (art. 803 ter a.4 LECR). No tendrían que plantearse dudas con relación al valor jurídico que hay que dar a esta actitud del

65 El art. 7.4 DIR 2016/343/UE del Parlamento Europeo y del Consejo, de 9 de marzo de 2016, por la que se refuerzan en el proceso penal determinados aspectos de la presunción de inocencia y el derecho a estar presente en el juicio, y sobre el derecho a que se informe a un tercero en el momento de la privación de libertad y a comunicarse con terceros y con autoridades consulares durante la privación de libertad [DOUE n. L 65, de 11 de marzo de 2016], autoriza a los Estados miembros para que sus órganos jurisdiccionales puedan, al dictar sentencia, tomar en consideración un comportamiento cooperador por parte de los sospechosos o acusados. 
tercero en ejercicio de su estrategia defensiva: solamente renuncia a defenderse directamente, a presencia judicial, de la conducta de mala fe con relación a bienes del investigado o encausado que le formula el Ministerio Fiscal o alguna de las acusaciones, pero nada más. Por tanto, es una renuncia a participar en un acto procesal referido al posible decomiso de bienes suyos, al cual no se opone, pero no puede significar que está aceptando la procedencia del mismo y su imposición sin más trámites y consideraciones en la sentencia, que tenemos que volver a recordar una vez más que tiene como presupuesto una previa conducta suya de mala fe que le puede suponer incluso tener que responder penalmente por ella. El Fiscal y las acusaciones tienen que pedir y probar la adecuación a las normas del decomiso de bienes de la tercera persona, y el órgano judicial reputarlo suficiente.

j) Facultad de no convocar: La Ley de Enjuiciamiento Criminal autoriza al órgano judicial a no convocar al procedimiento a los terceros afectados cuando se dé alguna de las siguientes situaciones desagregadas del contenido del art. 803 ter a.2 LECR:

1. $\left.{ }^{a}\right)$ Si no se ha podido identificar al posible titular de los derechos sobre el bien cuyo decomiso se solicita ${ }^{66}$; o si no se ha podido localizar al posible titular de los derechos sobre el bien cuyo decomiso se solicita ${ }^{67}$. En cualquiera de estas dos situaciones, desde el momento en el que haya constancia de la existencia de una tercera persona con derechos sobre los bienes decomisables, o conocida, siendo posible su localización y comunicación para incorporarse a las actuaciones judiciales para defenderse, habrá que proceder diligentemente de la manera ordinaria

66 Esta circunstancia es coherente con la catalogación de tercero contenida en el apartado anterior del mismo art. 803 ter a.1 LECR: (i) que los bienes a decomisar estén identificados, pero que el órgano judicial $-\mathrm{y}$ las acusaciones- piensen que son de la propiedad del encausado en el proceso penal principal, y que por tanto no hay tercera persona alguna a la que citar como propietarios de los mismos; o (ii) que los bienes a decomisar estén identificados y acreditada su propiedad por el encausado en el proceso penal principal, y que el órgano judicial - y las acusaciones- piensen que sobre los mismos no hay ninguna tercera persona que tenga derechos distintos a la propiedad.

67 A diferencia del anterior caso, en este sí se sabe que hay una persona con derechos sobre los bienes a decomisar, pero han fracasado los actos de comunicación tenidos con él. 
vista, puesto que la amenaza que se cierne sobre las actuaciones que se practiquen es la misma: si se acuerda el decomiso de los bienes de esa persona, bien conociendo de su existencia y sin que se tomen medidas al respecto, o bien estando localizada pero sin comunicarse con ella, cuando tome conocimiento de la resolución en la que se acuerde el decomiso de bienes suyos podrá pedir la rescisión de la misma (art. 803 ter d LECR).

2. a) Si existen hechos de los que pueda derivarse que la información en que se funda la pretensión de intervención en el procedimiento no es cierta. Esta previsión trata de impedir comparecencias fraudulentas y dilatorias con las actuaciones procesales, y está pensada esencialmente para cuando el juzgado o tribunal tiene que analizar la petición que le haya cursado, ora el investigado o encausado, ora el propio tercero, de quien defendemos que está legitimado. Al no darse los presupuestos analizados, el control de legalidad resultante es negativo y por tanto procede no incorporar a esa tercera persona al proceso penal en curso.

3. a) Si existen hechos de los que pueda derivarse información de que los supuestos titulares de los bienes a decomisar son personas interpuestas, vinculadas al investigado o encausado. Esta exclusión, construida sobre las expresiones «supuestos titulares»y «personas interpuestas vinculadas» - testaferros-, no se entiende por qué ha sido acogida por el legislador, al menos tal y como ha sido prevista en el articulado de la Ley de Enjuiciamiento Criminal ${ }^{68}$.

68 Porque (i) si está acreditado que son propietarios de los bienes, o titulares de otros derechos, no son «supuestos titulares» y tienen que ser llamados para defenderse del decomiso que se pueda acordar contra sus bienes, justificado si el traspaso de la propiedad - o de los derechos sobre los bienes- se ha hecho de mala fe; (ii) si está acreditado que no son verdaderos titulares de derechos sobre los bienes, es correcto no llamarlos al proceso penal principal - no se daría el presupuesto habilitante-, pero entonces en este caso habría que analizar si hay que proceder penalmente contra ellos por su conducta obstruccionista; y (iii) si se duda si son o no titulares de derechos sobre los bienes, aunque a priori no tendría sentido ampliar el objeto del proceso penal principal para cuestionar la legitimidad de la relación de esa persona con el investigado o encausado y con sus bienes, si con posterioridad no se quieren sufrir - eventualmente-las consecuencias materiales y procesales de una rescisión de la sentencia que se dicte acordando el decomiso de sus bienes, sin haber hecho efectivos los derechos de audiencia y contradicción, la prudencia llevaría a llamarlo al proceso, y, como en el caso anterior, si lo procedente es actuar penalmente contra él. 
4. ${ }^{\text {a) }}$ Si existen hechos de los que pueda derivarse información de que los supuestos titulares de los bienes cuyo decomiso se solicita son personas interpuestas vinculadas al investigado - o encausado-. Como en el caso anterior, y casi con más razón, a nuestro juicio carece de sentido la exclusión. La decisión a tomar es binaria: o son titulares de derechos y tienen que ser citados, o no lo son y puede obviarse su llamamiento. No hay situaciones intermedias. Aparte de ello, parece que las exigencias derivadas de la legalidad penal mal se compadecen con expresiones en las que se presume carácter delictivo a situaciones tan ambiguas como ser persona interpuesta y vinculada al investigado o encausado.

k) Remedios procesales: La resolución por la que el juzgado o tribunal declare improcedente la intervención del tercero en el procedimiento podrá ser pasible de recurso de apelación (art. 803 ter a.3 LECR). Muy restringido está el derecho al recurso en este trámite de intervención en el proceso penal de los terceros que puedan resultar afectados por el decomiso. A nuestro juicio, el poder formular un medio de impugnación como la apelación tiene que ser un derecho reconocible ante cualquier resolución sobre esta materia, sin tomar en cuenta su contenido - favorable o desfavorable a la intervención - ni de quién ha procedido la iniciativa de plantear la misma en el desarrollo del proceso penal principal. Todos deberían estar interesados en ello: (i) el tercero, porque de acordarse su intervención, además de poder perder sus bienes en favor del Estado puede tener que responder penalmente por su conducta con relación a esos bienes y al investigado o encausado; (ii) el investigado - o encausado-, porque en caso de que se acredite que tuvo bienes de procedencia ilícita en caso de que los mismos no se encuentren y/o no se recuperen, por mor de un decomiso directo, puede ver como con relación a su patrimonio se pueden acordar otras modalidades de decomiso; (iii) el Ministerio Fiscal, las acusaciones y la víctima, eventuales beneficiarias de la realización de los bienes decomisados; y (iv) el mismo Estado, para integrar los bienes decomisados en las arcas públicas y poder cubrir las finalidades que con ellos tiene prevista la normativa vigente.

l) Asistencia letrada: El tercero, para intervenir en el proceso penal $-\mathrm{y}$ en la eventual fase impugnativa-, tiene que estar asistido por un abogado, preceptivamente (art. 803 ter b.2 LECR). Este letrado puede ser elegido por él, y en el caso de que no haga su designación una vez que 
reciba la comunicación judicial convocándole a las actuaciones procesales el juzgado o tribunal competente tendrá que proceder a su designación de oficio. Esta intervención del tercero puede hacerla de manera personal o por medio de su representante legal, puesto que el art. 803 ter b.3.II LECR no condiciona la validez de los actos procesales a que el tercero afectado esté presente físicamente en las actuaciones.

m) Amplitud defensiva: La intervención del tercero llamado al proceso se va a producir con plenitud de facultades defensivas, alegatorias e impugnatorias, pero con una importante doble restricción en su ámbito de actuación (art. 803 ter b.1 LECR): (i) tendrá que limitarse a los aspectos que afecten directamente a sus bienes, derechos o situación jurídica; y (ii) no podrá extenderse a las cuestiones relacionadas con la responsabilidad penal del encausado. La persona afectada por el decomiso hasta el momento en el que se ha apreciado la necesidad de su intervención en el proceso penal era un tercero. De hecho, como hemos indicado, nunca ese tercero pudo ser parte en el proceso penal principal. Ahora bien, desde el momento en el que se produce su entrada en el proceso, y hasta que la sentencia alcance su firmeza, este tercero debería ser considerado parte, pasiva, como el encausado y el responsable civil, y por eso se le pide que actúe asistido por un letrado. De no ser así, no se entiende cómo se va a articular su participación en unas actuaciones que pueden tener consecuencias sancionadoras para él, ni cómo sin esa condición va a estar legitimado, por ejemplo, para formular medios de impugnación frente a la resolución que resuelva en la instancia el proceso penal principal.

Además de esta primera consideración nuclear, que condiciona todo el régimen jurídico del tercero afectado, tenemos que comentar: (i) la prohibición tiene que alcanzar, consideramos, también a los aspectos relacionados con la responsabilidad civil del encausado, con la que claramente existen más vínculos patrimoniales al menos en orden a la investigación, identificación de bienes, su aseguramiento cautelar, etc.; (ii) es lógica la limitación, en términos generales, porque es justamente el ámbito en el que se encuadra su declaración en las actuaciones lo que ha justificado su llamada a intervenir en el proceso penal; (iii) es muy difícil deslindar, en particular, cada acto del tercero con relación a esos elementos, por lo que el órgano judicial debería ser generoso y, a la vez, vigilante con las extralimitaciones de la tercera persona, en la admisión de 
los mismos, no solo para no cercenar el contenido material de los derechos de audiencia, contradicción y defensa, sino porque además cuestiones y hechos que le pueden valer para eximir a sus bienes del decomiso y a él de responsabilidad penal a buen seguro que serán concomitantes con los que permitirán o negarán la responsabilidad penal - y civil- del encausado o investigado; (iv) el legislador parece pensar sólo en que acuda al juicio oral - $\mathrm{o}$ ante el juez instructor - para declarar - como testigo-, pero para que su derecho de defensa sea verdaderamente efectivo tiene que tener la oportunidad no sólo de alegar e impugnar las resoluciones que se dicten, sino también de probar sus afirmaciones, para lo cual, primero, tiene que habérsele dado conocimiento de todas las actuaciones practicadas con relación a sus bienes y su relación - fraudulenta, encubridora, obstruccionista...- con el investigado o encausado, y, segundo, si lo pide, un tiempo prudencial para que su defensa se prepare en orden a la proposición y práctica de medios de prueba, lo que no será tan necesario si la intervención se produce antes de las sesiones del juicio oral cuando, por ejemplo, se adopten medidas cautelares sobre los bienes; $\mathrm{y}(v)$ es erróneo construir toda esta estructura de participación del tercero presumiendo como única posibilidad que, inclusive en el proceso penal, el investigado o encausado y el tercero estén confabulados para que con las actuaciones de ambos se puedan eludir las responsabilidades imputadas a cada uno de ellos. No serán infrecuentes los casos en que ambos estén distanciados en sus posicionamientos jurídicos y en sus estrategias defensivas, e incluso, enfrentados: el tercero y el investigado o encausado pueden querer presentar elementos incriminatorios frente al otro para recibir un tratamiento premiado por parte de la acusación pública.

Estas mismas limitaciones tiene extensión a la fase de impugnación para cuando el afectado por el decomiso interponga frente a la sentencia en la que lo acuerde uno de los recursos previstos legalmente. En ese momento, también tiene que circunscribir su recurso a los pronunciamientos que afecten directamente a sus bienes, derechos o situación jurídica, y no podrá extenderlo a las cuestiones relacionadas con la responsabilidad penal del encausado (art. 803 ter c in fine LECR).

n) Consecuencias de la falta de comparecencia: Citado en tiempo y forma el tercero afectado por el decomiso, su incomparecencia en el tiempo marcado en la comunicación judicial determinará que se le declare en 
rebeldía. Esta situación jurídica, según prevé el art. 803 ter d LECR, se va a regir por las normas establecidas en la Ley de Enjuiciamiento Civil para con el demandado rebelde, incluidas las previstas para las notificaciones, los recursos frente a la sentencia y la rescisión de la sentencia firme a instancia del rebelde. Cuando el tercero afectado por el decomiso sea citado a las sesiones del juicio oral, haya intervenido o no previamente en las actuaciones judiciales, se le va a tener que informar expresamente de dos cuestiones (art. 803 ter b.4.I LECR): (i) que el juicio podrá ser celebrado en su ausencia y, además, (ii) que en el mismo podrá resolverse, en todo caso, sobre el decomiso solicitado. A consecuencia de lo que acabamos de señalar, el art. 803 ter b.4 LECR establece que la incomparecencia del afectado por el decomiso no impedirá la continuación del juicio. Aunque no se dice, una ausencia voluntaria y querida ${ }^{69}-v$. gr., casos de fuerza mayor $^{70}-$, puesto que en caso de que no lo fuera si el juicio se celebrara y se acordara en la sentencia de condena el decomiso de bienes suyos, esta resolución podría ser rescindida (art. 803 ter d.1.I LECR) ${ }^{71}$.

69 El art. 8 DIR 2016/343/UE reconoce el «derecho a estar presente en el juicio», el cual tiene que ser garantizado por todos los Estados miembros. No obstante, se permite que los países, aun en ausencia del acusado o sospechoso, puedan celebrar juicios que puedan dar lugar a una resolución de condena o absolución del sospechoso o acusado, siempre y cuando se cumplan una de estas dos condiciones para que la resolución pueda ser ejecutada: a) que el sospechoso o acusado haya sido oportunamente informado del juicio y de las consecuencias de la incomparecencia; o b) que el sospechoso o acusado, tras haber sido informado del juicio, esté formalmente defendido por un letrado designado o bien por el sospechoso o acusado o bien por el Estado.

70 En el proceso civil, a cuyas normas se remite en esta materia el art. 803 ter d LECR, la rescisión de sentencias firmes a instancia del demandado que haya permanecido constantemente en rebeldía puede tener lugar en los tres casos establecidos en el art. 501 LEC: a) fuerza mayor ininterrumpida, que impidió al rebelde comparecer en todo momento, aunque haya tenido conocimiento del pleito por haber sido citado o emplazado en forma; $b$ ) desconocimiento de la demanda y del pleito, cuando la citación o emplazamiento se hubieren practicado por cédula, conforme al art. 161 LEC, pero ésta no hubiese llegado a poder del demandado rebelde por causa que no le sea imputable; y c) desconocimiento de la demanda y del pleito, cuando el demandado rebelde haya sido citado o emplazado por edictos y haya estado ausente del lugar en que se haya seguido el proceso y de cualquier otro lugar del Estado o de la Comunidad Autónoma, en cuyos Boletines Oficiales se hubiesen publicado aquéllos.

71 El art. 9 DIR 2016/343/UE obliga a los Estados miembros a que velen por que, cuando los sospechosos o acusados no estén presentes en el juicio y no 
El afectado por el decomiso podrá actuar en el juicio por medio de su representación legal, sin que sea necesaria su presencia física en el mismo (art. 803 ter b.4.II LECR).

La sentencia en la que se acuerde el decomiso será notificada a la persona afectada por el mismo, aunque no hubiera comparecido en el proceso (art. 803 ter c LECR), bien porque manifestó al juez o tribunal que no se oponía al decomiso, bien porque esta persona se encontraba en una de las dos situaciones previstas en el art. 803 ter a.2 LECR ya analizadas.

o) Rescisión de la sentencia: La sentencia aludida puede ser objeto de rescisión a instancia del tercero afectado, con la limitación en el planteamiento y en las facultades del conocimiento del órgano jurisdiccional ya reseñada: el juicio rescindente estará circunscrito únicamente a los pronunciamientos que afecten directamente al tercero en sus bienes, derechos o situación jurídica (art. 803 ter d.1.I LECR). Estamos ante una rescisión penal de una condena penal, aunque se tramite por muchas de las disposiciones de los arts. 501 y siguientes LEC, solicitada por un sujeto que con relación al inicio y desarrollo del proceso principal fue un tercero, pero que desde que fue llamado a las actuaciones se le legitima para defender en condiciones de igualdad que al penado la defensa de sus intereses jurídicos.

En la sustanciación del procedimiento, tras la sentencia estimatoria, no se van a seguir los trámites establecidos en los artículos 507 y 508 LEC, ya que los mismos son excepcionados por el art. 803 ter d.1.I LECR, en el que se señalan las siguientes reglas particulares: (i) al juzgado o tribunal que hubiera dictado la sentencia en primera instancia, en el caso de que fuera distinto al que hubiera dictado la sentencia rescindente, se le va a remitir certificación de la sentencia; (ii) al tercero se le dará un plazo de diez días para presentar un escrito de contestación a la demanda de

se cumplan las dos condiciones ya referenciadas en la nota anterior, estos tengan derecho a un nuevo juicio, u otras vías de recurso, que permita una nueva apreciación del fondo del asunto, incluido el examen de nuevas pruebas, y pueda desembocar en la revocación de la resolución original. En este sentido, los Estados miembros garantizarán que dichos sospechosos o acusados tengan derecho a estar presentes, a participar efectivamente, de conformidad con los procedimientos previstos en el Derecho nacional, y a ejercer su derecho de defensa. 
decomiso, con proposición de prueba, manteniéndose la limitación: los medios de prueba tendrán que tener relación con los hechos relevantes para el pronunciamiento que le afecte; (iii) si el escrito ha sido presentado en plazo por el tercero afectado, el órgano jurisdiccional resolverá sobre la admisibilidad de prueba mediante un auto y, con arreglo a las normas generales, se señalará fecha para la vista, cuyo objeto se ceñirá al enjuiciamiento de la acción civil planteada contra el tercero o de la afección de sus bienes, derechos o situación jurídica por la acción penal; (iv) frente a la sentencia se podrán interponer los recursos previstos en la Ley de Enjuiciamiento Criminal; y (v) si no se presenta escrito de contestación a la demanda en plazo, o el tercero no comparece en la vista debidamente representado, se dictará, sin más trámite, sentencia coincidente con la rescindida en los pronunciamientos afectados.

\section{CONCLUSIONES}

Históricamente el proceso penal se centró en establecer la responsabilidad de las personas - físicas- que tomaron parte en la comisión del delito. Poca o ninguna atención se prestó, en esos momentos, a realizar investigaciones patrimoniales tendentes a obtener el decomiso del producto del delito.

Con el tiempo se adquirió cabal conciencia de que el Derecho Penal no puede alcanzar sus altas finalidades sólo con operar sobre el encarcelamiento de personas, en particular en aquellas actividades delictivas que generan altos y regulares rendimientos económicos. En estos casos, una forma eficiente de acabar con la espiral delictiva es actuar sobre esos rendimientos.

Como hemos tenido oportunidad de exponer, el legislador español en este caso- ingresó entonces en una espiral normativa. En efecto, cada avance se tornaba, al poco tiempo, en ineficaz, frustrándose las esperanzas de operar el decomiso con menores requisitos de aquello que se avizoraba como esquivo: la acreditación de la responsabilidad penal. Esa desazón daba pie así a un nuevo ciclo de avance legislativo, para lograr mayor eficacia. Ese ciclo exhibió una secuencia por demás clara: bienes originarios, bienes subrogantes, bienes equivalentes, hasta llegar a los bienes de terceros. 
La vorágine legislativa tiene una razón evidente: la dificultad probatoria. En efecto, en los delitos complejos ${ }^{72}$ no es fácil reunir prueba suficiente sobre el vínculo doloso que puede existir entre el tercero y el autor del delito ${ }^{73}$, o sobre la mala fe conque adquirió su derecho. Pero, además, existe una razón adicional, para nada despreciable: la puesta en crisis del derecho de propiedad, cuando hace a la indagación sobre la licitud o no de su origen, es un aspecto particularmente sensible para la estructura del orden constitucional y democrático. Cuando la buena fe es norma, las políticas que promueven el decomiso deben ser particularmente cuidadosas, so pena de que las loables metas que ellas persiguen queden reducidas a letra muerta.

\section{BIBLIOGRAFÍA}

AGUADO CORREA, Teresa. Comiso: crónica de una reforma anunciada. Análisis de la propuesta de Directiva sobre embargo y decomiso de 2012 y del Proyecto de reforma del Código Penal de 2013. InDret: Revista para el Análisis del Derecho, n. 1, p. 1-56, 2014.

AGUADO CORREA, Teresa: Artículo 127 quater. In: GÓMEZ TOMILLO, Manuel. Comentarios prácticos al Código Penal. Parte General. Tomo I. Pamplona: Aranzadi, p. 1031-1038, 2015.

ALLDRIDGE, Peter. Money Laundering Law. Forfeiture, Confiscation, Civil Recovery, Criminal Laundering and Taxation of the Proceeds of Crime. London: Hart Publishing, 2003. https://doi.org/10.5040/9781472559340

ANTUNES, Maria João. Recuperación de activos. Garantías procesales del decomiso de bienes en el Derecho portugués. In: BERDUGO GÓMEZ DE LA TORRE, Ignacio: FABIÁN CAPARRÓS, Eduardo Ángel; RODRÍGUEZ-GARCÍA, Nicolás (edits.). Decomiso y recuperación de activos. Crime doesn't pay. Valencia: Tirant lo Blanch, 2020 - en prensa-.

BOUCHT, Johan. The Limits of Asset Confiscation. On the Legitimacy of Extended Appropriation of Criminal Proceeds. London: Hart Publishing, 2017. https://doi. org/10.5040/9781509907106

72 Sobre ellos vid. ORSI, Omar Gabriel. Aportes metodológicos a la investigación y prueba de casos complejos. RODRÍGUEZ-GARCÍA, Nicolás; RODRÍGUEZ LÓPEZ, Fernando (coords). Corrupción y desarrollo. Valencia: Tirant lo Blanch, p. 385 y ss., 2017.

Cfr. SÁNCHEZ SISCART, José Manuel. Intervención de terceros..., cit., p. 8. 
BRUN, Jean-Pierre; GRAY, Larissa; SCOTT, Clive; STEPHENSON, Kevin M. Asset Recovery Handbook: A Guide for Practitioners. Washington: The International Bank for Reconstruction and Development / The World Bank, p. 103 y ss., 2011. https://doi.org/10.1596/978-0-8213-8634-7

BUJOSA VADELL, Lorenzo Mateo. La perspectiva procesal del decomiso. In: CASTILLEJO MANZANARES, Raquel (dir.). El nuevo proceso penal sin Código Procesal Penal. Barcelona: Atelier, p. 677-718, 2019.

CAMPOS NAVAS, Daniel. Otras modalidades de decomiso: el decomiso ampliado, el decomiso de bienes de tercero y el decomiso sin sentencia condenatoria. In: VV.AA. El decomiso: aspectos sustantivos y procesales. Madrid: Centro de Estudios Jurídicos, p. 1-21, 2019.

CARPIO DELGADO, Juana del. Decomiso de bienes transferidos a terceros tras la reforma de 2015 del código penal. Cuadernos de Política Criminal, n. 122, p. 89-132, 2017.

CARRILLO DEL TESO, Ana Elena. Consideraciones sobre la actividad probatoria en torno a la delincuencia económica. Justicia: Revista de Derecho Procesal, n. 2, p. $485-548,2019$.

CARRILLO DEL TESO, Ana. Elena. Decomiso y recuperación de activos en el sistema penal español. Valencia: Tirant lo Blanch, 2018.

CARRILLO DEL TESO, Ana Elena. El nuevo régimen de recuperación de activos en Alemania o la sublimación del principio crime doesn't pay. In: BERDUGO GÓMEZ DE LA TORRE, Ignacio: FABIÁN CAPARRÓS, Eduardo Ángel; RODRÍGUEZ-GARCÍA, Nicolás (edits.). Decomiso y recuperación de activos. Crime doesn't pay. Valencia: Tirant lo Blanch, 2020 -en prensa-.

CASTELLVÍ MONSERRAT, Carlos. Decomisar sin castigar. Utilidad y legitimidad del decomiso de ganancias. InDret: Revista para el Análisis del Derecho, n. 1, p. 4-66, 2019.

CHOCLÁN MONTALVO, José Antonio. El patrimonio criminal. Comiso y pérdida de la ganancia. Madrid: Dykinson, 2011.

CONDE FUENTES, Jesús (2018). La intervención en el proceso penal de terceros afectados por el decomiso. Revista Penal, n. 42, p. 56-66, 2018.

DÍAZ LÓPEZ, Juan Alberto. El partícipe a título lucrativo tras las reformas del decomiso. Diario La Ley, n. 8667, p. 4-7, 2015.

DURÁN SILVA, Carmen. Las presunciones legales iuris tantum en la figura del decomiso. Revista General de Derecho Procesal, n. 48, p. 1-28, 2019.

FARTO PIAY, Tomás. Los terceros afectados por el decomiso ante el proceso penal. In: BERDUGO GÓMEZ DE LA TORRE, Ignacio: FABIÁN CAPARRÓS, Eduardo 
Ángel; RODRÍGUEZ-GARCÍA, Nicolás (edits.). Decomiso y recuperación de activos. Crime doesn't pay. Valencia: Tirant lo Blanch, 2020 - en prensa-.

FERNANDEZ-BERTIER, Michaël. The History of Confiscation Laws: From the Book of Exodus to the War on White-Collar Crime. In: LIGETI, Katalin; SIMONATO, Michele (eds.). Chasing Criminal Money. Challenges and Perspectives on Asset Recovery in the EU. London: Hart Publishing, p. 53-76, 2017. https://doi. org/10.5040/9781509912087.ch-002

GARCÍA CAVERO, Percy. El decomiso de bienes relacionados con el delito en la legislación penal peruana. Derecho PUCP, n. 81, p. 113-136, 2018. https://doi. org/10.18800/derechopucp.201802.004

GARRIDO CARRILLO, Francisco Javier (2019). El decomiso: innovaciones, deficiencias y limitaciones en su regulación sustantiva y procesal. Madrid: Dykinson. https://doi.org/10.2307/j.ctvk3gnhs

GASCÓN INCHAUSTI, Fernando. Las nuevas herramientas procesales para articular la política criminal de decomiso total: La intervención en el proceso penal de terceros afectados por el decomiso y el proceso para el decomiso autónomo de los bienes y productos del delito. Revista General de Derecho Procesal, n. 38, p. 1-71, 2016.

GÓMEZ TOMILLO, Manuel. La responsabilidad civil de las personas jurídicas: especial problemática del tercero lucrativo. Cuadernos Digitales de Formación, n. 19, p. 1-19, 2016.

GONZÁLEZ CANO, María Isabel. El decomiso como instrumento de la cooperación judicial en la Unión Europea y su incorporación al proceso penal español. Valencia: Tirant lo Blanch, 2016.

GONZÁLEZ-CUÉLLAR SERRANO, Nicolás. Aspectos procesales del decomiso: intervención de terceros afectados por el decomiso, el proceso de decomiso autónomo y la Oficina de Recuperación y Gestión de Activos. In: MARCHENA GÓMEZ, Manuel; GONZÁLEZ-CUÉLLAR SERRANO, Nicolás. La reforma de la Ley de Enjuiciamiento Criminal en 2015. Madrid: Castillo de Luna, p. 439-520, 2016.

HAVA GARCÍA, Esther. La nueva regulación del comiso. In: QUINTERO OLIVARES, Gonzalo (coord.). Comentarios a la reforma penal de 2015. Pamplona: Aranzadi, p. 213-223, 2015.

JIMÉNEZ-VILLAREJO FERNÁNDEZ, Francisco. La nueva regulación del decomiso y la recuperación de activos delictivos en el ordenamiento jurídico español. Revista del Ministerio Fiscal, n. 0, p. 94-145, 2015.

MARTÍN PÉREZ, José Antonio. El comiso de bienes de propiedad de «tercero»: Análisis del respeto de las reglas sobre titularidad por las sentencias penales (A 
propósito del Auto TC 125/2004, de 19 de abril). Derecho Privado y Constitución, n. 205, p. 225-258, 2005.

MARTÍN SAGRADO, Óscar. El decomiso de las sociedades pantalla. Diario La Ley, n. 8768, p. 1-9, 2016.

MARTÍN SAGRADO, Óscar. El decomiso en la investigación y enjuiciamiento del delito de blanqueo de capitales». Revista General de Derecho Penal, n. 31, p. 1-32, 2019.

MARTÍNEZ-ARRIETA MÁRQUEZ DE PRADO, Cristina. El decomiso y la recuperación y gestión de activos procedentes de actividades delictivas. Valencia: Tirant lo Blanch, 2018.

MAUGERI, Anna Maria. La trasposición de la Directiva 2014/42/UE en Italia. In: BERDUGO GÓMEZ DE LA TORRE, Ignacio: FABIÁN CAPARRÓS, Eduardo Ángel; RODRÍGUEZ-GARCÍA, Nicolás (edits.). Decomiso y recuperación de activos. Crime doesn't pay. Valencia: Tirant lo Blanch, 2020 - en prensa-.

NIEVA FENOLL, Jordi. El procedimiento de decomiso autónomo. En especial, sus problemas probatorios. Diario La Ley, n. 8601, p. 1-8, 2015.

NOREÑA SALTO, José Ramón. El procedimiento de decomiso autónomo. In: VV.AA. El decomiso: aspectos sustantivos y procesales. Madrid: Centro de Estudios Jurídicos, p. 1-21, 2019.

OCAÑA RODRÍGUEZ, Antonio. Medidas cautelares reales en el proceso penal y decomiso. Madrid: Sepín, 2016.

ORSI, Omar Gabriel. Aportes metodológicos a la investigación y prueba de casos complejos. In: RODRÍGUEZ-GARCÍA, Nicolás; RODRÍGUEZ LÓPEZ, Fernando (coords). Corrupción y desarrollo. Valencia: Tirant lo Blanch, p. 393-426, 2017.

PLANCHADELL GARGALLO, Andrea; VIDALES RODRÍGUEZ, Catalina. Decomiso: comentario crítico desde una perspectiva constitucional. Estudios Penales y Criminológicos, n. 38, p. 37-92, 2018. https://doi.org/10.15304/epc.38.5017

QUINTERO OLIVARES, Gonzalo. Sobre la ampliación del comiso y el blanqueo, y la incidencia en la receptación civil. Revista Electrónica de Ciencia Penal y Criminología, n. 12-rl, p. 1-20, 2010.

QUINTERO OLIVARES, Gonzalo. El procedimiento especial y autónomo para el comiso. In: QUINTERO OLIVARES, Gonzalo (coord.). Comentarios a la reforma penal de 2015. Pamplona: Aranzadi, p. 297-310, 2015.

RAMOS MÉNDEZ, Francisco. El sistema procesal español (9. ed.). Barcelona: Atelier, 2013. 
RASILLO LÓPEZ, Pilar. El decomiso. Cuadernos Digitales de Formación, n. 3, p. 1-24, 2017.

RODRÍGUEZ-GARCÍA, Nicolás. Redescubrimiento de las bonanzas del decomiso en las tácticas supranacionales e internacionales para poner freno a la «sociedad incivil». In: BERDUGO GÓMEZ DE LA TORRE, Ignacio; FABIÁN CAPARRÓS, Eduardo Ángel; RODRÍGUEZ-GARCÍA, Nicolás (coords.). Recuperación de activos $y$ decomiso. Reflexiones desde los sistemas penales iberoamericanos. Valencia: Tirant lo Blanch, p. 317-384, 2017.

RODRÍGUEZ-GARCÍA, Nicolás. El decomiso de activos ilícitos. Pamplona: Aranzadi, 2017.

ROIG TORRES, Margarita. El comiso como estrategia frente a la corrupción en Alemania: interpretación jurisprudencial. Estudios Penales y Criminológicos, n. extra 38, p. 547-604, 2018. https://doi.org/10.15304/epc.38.4473

RUZ GUTIÉRREZ, Pablo Rafael. Prevención, sanción y recuperación de activos de la corrupción: la experiencia española. In: FERNÁNDEZ BLANCO, Carolina; FERRER BELTRÁN, Jordi (dirs.). Seguridad jurídica, pobreza y corrupción en Iberoamérica. Madrid: Marcial Pons, p. 185 y ss. https://doi.org/10.2307/j.ctv10sm8mb

SÁEZ-SANTURTÚN PRIETO, Miguel. El responsable civil a título lucrativo: artículo 122 del Código Penal. Diario La Ley, n. 8497, p. 1-6, 2015.

SÁNCHEZ SISCART, José Manuel. Intervención de terceros afectados por el decomiso y el decomiso autónomo. La recuperación y gestión de activos. Formación a Distancia, n. 3, p. 1-40, 2016.

TRINCHERA, Tommaso. Confiscation and asset recovery: Better tools to fight bribery and corruption crime. Criminal Law Forum, p. 1-31, 2020. https://doi. org/10.1007/s10609-020-09382-1

URIARTE VALIENTE, Luis María. 21 cuestiones sobre el decomiso: Disposiciones generales, decomiso directo y de sustitución. In: VV.AA. El decomiso: aspectos sustantivos y procesales. Madrid: Centro de Estudios Jurídicos, p. 1-24, 2019.

VV.AA. Common Law Legal Systems Model Legislative Provisions on Money Laundering, Terrorism Financing, Preventive Measures and Proceeds of Crime. London: Commonwealth Secretariat, 2016. https://doi.org/10.14217/9781848599444-en VIDALES RODRÍGUEZ, Catalina; PLANCHADELL GARGALLO, Andrea. Decomiso: Estudio de la normativa internacional y de la legislación española (Aspectos penales y procesales). Miami (Florida). Center for the Administration of Justice, 2018.

VIDALES RODRÍGUEZ, Catalina. Consecuencias accesorias: Decomiso (arts. 127 a 127 octies). In: GONZÁLEZ CUSSAC, José Luis (dir.). Comentarios a la Reforma del Código Penal de 2015. Valencia: Tirant lo Blanch, p. 391-414, 2015. 


\section{Informações adicionais e declarações dos autores (integridade científica)}

Declaração de conflito de interesses (conflict of interest declaration): os autores confirmam que não há conflitos de interesse na realização das pesquisas expostas e na redação deste artigo.

Declaração de autoria e especificação das contribuições (declaration of authorship): todas e somente as pessoas que atendem os requisitos de autoria deste artigo estão listadas como autores; todos os coautores se responsabilizam integralmente por este trabalho em sua totalidade.

- Nicolás Rodríguez-García: projeto e esboço inicial (conceptualization), desenvolvimento da metodologia (methodology), coleta e análise de dados (data curation), levantamento bibliográfico (investigation), revisão bibliográfica (investigation), redação (writing - original draft), participação ativa nas discussões dos resultados (validation), revisão crítica com contribuições substanciais (writing - review and editing), aprovação da versão final.

- Omar Gabriel Orsi: desenvolvimento da metodologia (methodology), coleta e análise de dados (data curation), levantamento bibliográfico (investigation), revisão bibliográfica (investigation), redação (writing - original draft), participação ativa nas discussões dos resultados (validation), revisão crítica com contribuições substanciais (writing - review and editing), aprovação da versão final.

Declaração de ineditismo e originalidade (declaration of originality): os autores asseguram que o texto aqui publicado não foi divulgado anteriormente em outro meio e que futura republicação somente se realizará com a indicação expressa da referência desta publicação original; também atestam que não há plágio de terceiros ou autoplágio. 
Dados do processo editorial

(http://www.ibraspp.com.br/revista/index.php/RBDPP/about/editorialPolicies)

- Recebido em: 31/03/2020

Equipe editorial envolvida

- Controle preliminar e verificação de plágio:

- Editor-chefe: 1 (VGV) 31/03/2020

- Avaliação 1: 23/04/2020

- Editor-associado: 1 (JJEC)

- Avaliação 2: 23/04/2020

- Revisores: 2

- Decisão editorial preliminar: 05/05/2020

- Retorno rodada de correções: 14/05/2020

- Decisão editorial final: 17/05/2020

\section{COMO CITAR ESTE ARTIGO:}

RODRÍGUEZ-GARCÍA, Nicolás; ORSI, Omar Gabriel. La protección reforzada en España de los terceros afectados por el decomiso de bienes ilícitos. Revista Brasileira de Direito Processual Penal, Porto Alegre, vol. 6, n. 2, p. 539-576, mai./ago. 2020. https://doi.org/10.22197/rbdpp.v6i2.360

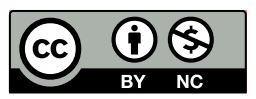

Esta obra está licenciada com uma Licença Creative Commons Atribuição-NãoComercial 4.0 Internacional. 